\title{
Successful surgical treatment of two patients with eosinophilic endomyocardial disease
}

\author{
J DAVIES, R SAPSFORD, I BROOKSBY, E G J OLSEN, C J F SPRY, \\ C M OAKLEY, J F GOODWIN
}

From the Departments of Medicine, Surgery, and Immunology, Royal Postgraduate Medical School, London; the Department of Histopathology, National Heart Hospital, London; and The Norfolk and Norwich Hospital, Norwich

SUMmaRy Cardiac surgery to treat severe heart failure was of benefit to two patients with endomyocardial disease and hypereosinophilia - eosinophilic endomyocardial disease. Both patients had severe biventricular fibrosis with mitral and tricuspid regurgitation. One had predominant right ventricular disease and was treated by right ventricular endocardectomy with tricuspid and mitral xenograft valve replacement. The second patient's main haemodynamic problem was considered to be mitral regurgitation. His mitral valve was replaced by a Starr-Edwards prosthesis; endocardectomy was not performed. Though both patients had toxic confusional states for several weeks postoperatively there was distinct symptomatic and objective evidence of improvement which has been maintained for over 16 months. Previous reports of surgical treatment of 22 patients without eosinophilia (all of whom had endomyocardial resection) and three other patients with eosinophilia have shown equally encouraging results. There has been no evidence of recurrence or progression of heart damage in follow-up periods of up to seven years. It is concluded that cardiac surgery is an important advance in the treatment of endomyocardial disease in patients with or without an eosinophilia.

Cardiac surgery for endomyocardial fibrosis was introduced by Gerbaux et al. ${ }^{1}$ The procedure involved removal of the fibrotic and thrombotic endocardial tissues, with replacement or repair of involved mitral and/or tricuspid valves. It was shown to be safe and effective $^{2}$ and there are now reports of over 22 patients treated in this way. Surgery is now generally accepted as an important advance in the management of this condition. ${ }^{3}$

In 1973 it was also recognised that Löffler's endomyocardial disease and tropical endomyocardial fibrosis were pathologically indistinguishable ${ }^{4}$ which supported earlier suggestions that they had a similar pathogenesis, reviewed by Olsen and Spry. ${ }^{5}$ The term eosinophilic endomyocardial disease is now applied to both. ${ }^{6}$ The management of endomyocardial disease in patients with eosinophilia was, however, complicated by the problem that heart disease was part of a systemic disorder in which many different organs might become involved - the hypereosinophilic syndromes. Initial results of cardiac surgery in three patients, including one who had a successful mitral

Received for publication 16 February 1981 valve repair in $1973,{ }^{7}$ were promising, ${ }^{89}$ but it was not known whether there were any additional hazards in operating on such patients, or whether the cardiac lesions would progress. Endocardectomy, which was carried out in all patients who had endomyocardial disease without an eosinophilia, was not attempted in these three patients, possibly because it was thought that thrombotic and/or fibrotic lesions could recur on operative sites. The recent introduction of effective medical treatment for hypereosinophilic syndromes with steroids and cytotoxic drugs appears to have reduced the severity of tissue injury, but endomyocardial disease remains one of the most frequent and clinically important complications. ${ }^{10}$ In view of the limited benefits of diuretics in patients with severe heart failure and the lack of alternative forms of treatment, we were persuaded to study the effects of cardiac surgery in two patients. This report describes our experience, including the value of endocardectomy.

\section{Case reports and results}

CASE 1

A 36-year-old man presented with fever, erythe- 
matous skin lesions, weight loss, and moderately severe cardiac failure. He had had depressive episodes intermittently for 13 years, and a cough with sinusitis for one year. There were signs of tricuspid regurgitation and of right ventricular failure with a loud third heart sound. The left ventricle was hypertrophied with mitral regurgitation. Electrocardiograms showed left atrial hypertrophy, widespread low voltage, and ventricular extrasystoles. The heart was slightly enlarged on chest radiographs. There was an eosinophilia of $5.0 \times 10^{9} / 1$, with mature but vacuolated and degranulated eosinophils in blood films. Marrow eosinophils were increased but of normal morphology. No cause for the eosinophilia was found.

\section{Preoperative cardiac investigations}

These have been described in Chew et al. ${ }^{11}$ (case 6). In summary, cardiac catheterisation showed raised pressures (Table 1). On angiocardiography the apex of the right ventricle was seen to be completely obliterated (Fig. 1), and there was tricuspid regurgitation. The left ventricle was dilated, with mild mitral regurgitation and some apical occlusion (Fig. 2). He was considered to have the hypereosinophilic syndrome with systemic complications and right and left ventricular endomyocardial disease. Initially heart failure responded to treatment with bed rest and diuretics. He was given warfarin which he has continued. The severe systemic complications of the hypereosinophilic syndrome resolved on treatment with prednisolone $40 \mathrm{mg} /$ day which was stopped five months later though the cough and eosinophilia persisted. At this time he could walk several miles, but during the subsequent four years his exercise tolerance gradually decreased until he was unable to climb stairs. Electrocardiograms showed atrial flutter with variable atrioventricular nodal block and right axis deviation, and on ambulatory Holter monitoring frequent unifocal ventricular extrasystoles were seen. A second course of steroids, additional diuretics, and rest in bed did not improve the heart failure which now made him breathless on minimal exertion.

\section{Operative findings}

Dense white fibrous tissue covered the inflow tract and body of the right ventricle, affecting both chordae and papillary muscles of the tricuspid valve, which was contained in a dilated ring. A strip of fibrous tissue was dissected from the inner wall of the right ventricle (Fig. 3). The papillary muscles were divided and the tricuspid valve was replaced with a $35 \mathrm{~mm}$ internal diameter Carpentier Edwards xenograft. In the left ventricle the only visible lesion was a small area of fibrosis attached to the inferolateral half of the posterior mitral valve cusp, producing regurgitation. The mitral valve was replaced with a $33 \mathrm{~mm}$ internal diameter Carpentier Edwards xenograft.

\section{Pathology}

Macroscopy: The strip of thick fibrous endocardium from the right ventricle in which a papillary muscle was also embedded was $70 \times 38 \mathrm{~mm}$ in size and measured up to $6 \mathrm{~mm}$ in thickness.

The tricuspid valve was opaque and uniformly thickened but showed no obvious involvement by fibrotic process of endomyocardial disease.

The anterior leaflet of the mitral valve was not involved and showed minimal thickening of the clear zone and focal thickening of chordae, whereas the posterior leaflet was considerably thickened and matting of the chordae was seen.

Histology: In the thickened endocardium the typical arrangement into three zones was noted, consisting of loosely arranged connective tissue superficially, followed by dense collagen tissue. The lowest zone, closest to the myocardium, "the granulation tissue

Table 1 Summary of catheterisation findings of two patients with Löffler's endomyocardial disease before and after operation

\begin{tabular}{|c|c|c|c|c|c|}
\hline & Preoperative pre & $\begin{array}{l}\text { udies } \\
\qquad(\mathrm{mmHg})\end{array}$ & $\begin{array}{l}\text { Months } \\
\text { postop. }\end{array}$ & Postoperative pr & $\begin{array}{l}\text { tudies } \\
\qquad(m m H g)\end{array}$ \\
\hline $\begin{array}{l}\text { Case } 1 \\
\quad M \text {, age } 36\end{array}$ & $\begin{array}{l}\text { RA } \\
\text { RV } \\
\text { PA } \\
\text { LA } \\
\text { LV } \\
\text { Cardiac output }\end{array}$ & $\begin{array}{l}30 \\
30 / 12 \\
25 / 14 \\
22 \\
110 / 23 \\
3.71 / \mathrm{min}\end{array}$ & 7 & $\begin{array}{l}\text { RA } \\
\text { LV } \\
\text { Cardiac output }\end{array}$ & $\begin{array}{l}20 \\
100 / 18 \\
4.51 / \mathrm{min}\end{array}$ \\
\hline $\begin{array}{l}\text { Case } 2 \\
\text { M, age } 24\end{array}$ & $\begin{array}{l}\text { RA } \\
\text { RV } \\
\text { PA } \\
\text { Wedge } \\
\text { LV } \\
\text { Cardiac output }\end{array}$ & $\begin{array}{l}12 \\
54 / 12 \\
54 / 28 \\
16 \\
105 / 20 \\
2.81 / \mathrm{min}\end{array}$ & 4 & $\begin{array}{l}\text { RA } \\
\text { RV } \\
\text { PA } \\
\text { Wedge } \\
\text { LV } \\
\text { Cardiac output }\end{array}$ & $\begin{array}{l}4 \\
38 / 3 \\
38 / 20 \\
12 \\
110 / 10 \\
4.21 / \mathrm{min}\end{array}$ \\
\hline
\end{tabular}


Fig. 1 Right atrial angiocardiogram, case 1. (a), (c) before operation; $(b),(d)$ seven months after operation. $(a)$ and $(b)$ are at end-diastole and $(c)$ and $(d)$ at end-systole. Before operation the apex of the right ventricle was obliterated, but infundibular contraction was increased. After operation the apex filled better and improved ventricular contraction was seen.

layer", contained dilated vessels and a sparse chronic inflammatory infiltrate, consisting predominantly of lymphocytes.

The tricuspid valve showed uniform, non-specific thickening but along the line of closure vascular fibrotic tissue was present, resembling the granulation tissue layer. The posterior leaflet was involved by zonally arranged fibrosis which extended along the chordae tendineae and the basal zone (that is where the leaflet takes origin from its valve ring). The anterior leaflet was not involved.

Postoperative findings

Though cardiac failure after the operation improved rapidly, he developed a severe organic toxic confusional state without focal neurological features which gradually resolved over the next month. Six months after the operation he could climb stairs and walk several miles without difficulty, though he still needed to take frusemide 60 to $80 \mathrm{mg} /$ day and amiloride $15 \mathrm{mg} /$ day. Warfarin was continued. There were no clinical features of heart failure. The eosinophilia persisted unchanged. Cardiac catheterisation seven months after operation showed improved filling and contraction of the right ventricle. There was no evidence of progression of the disease in the left ventricle, and there were no features to suggest recurrence at the endocardectomy site (Fig. 1). 

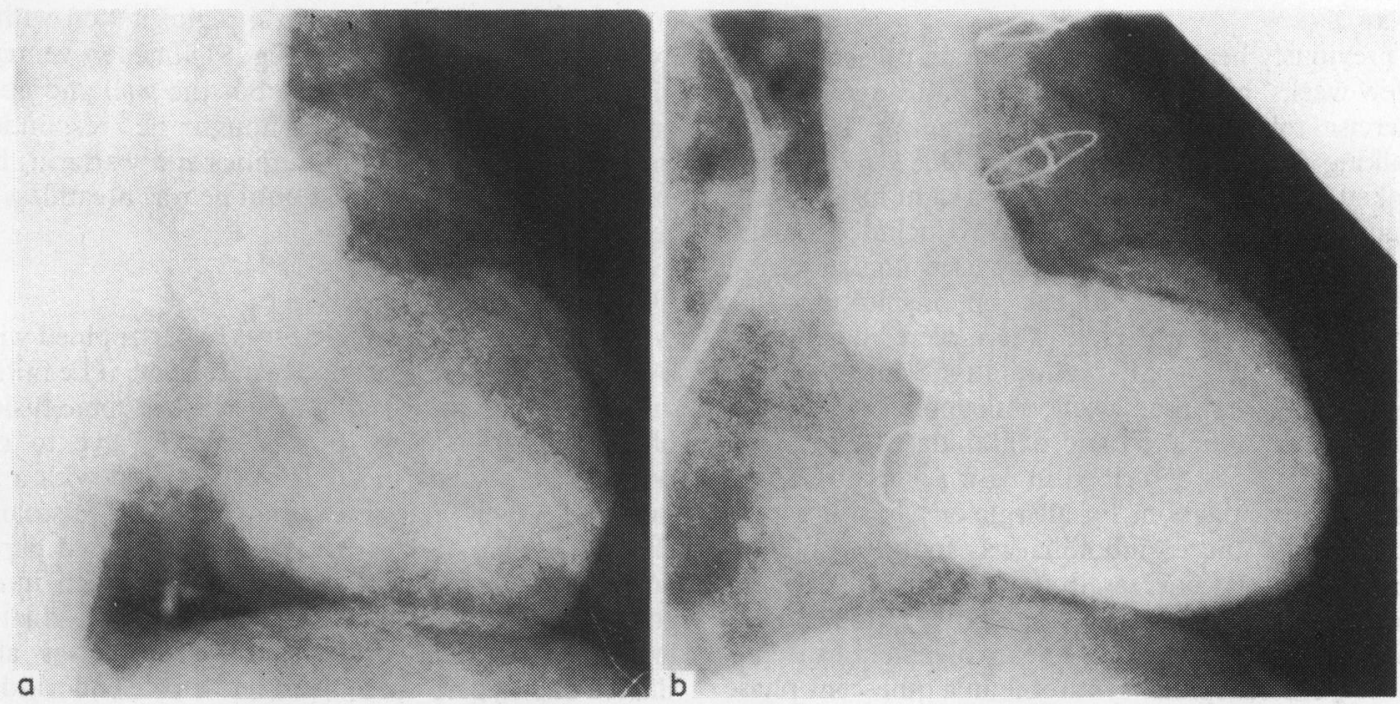

Fig. 2 Left ventricular angiogram, case 1. (a) four years before operation and (b) seven months after operation. No mitral regurgitation was seen postoperatively after mitral valve xenograft replacement, but the left ventricular irregularities were unchanged, suggesting no progression of the endomyocardial fibrosis.

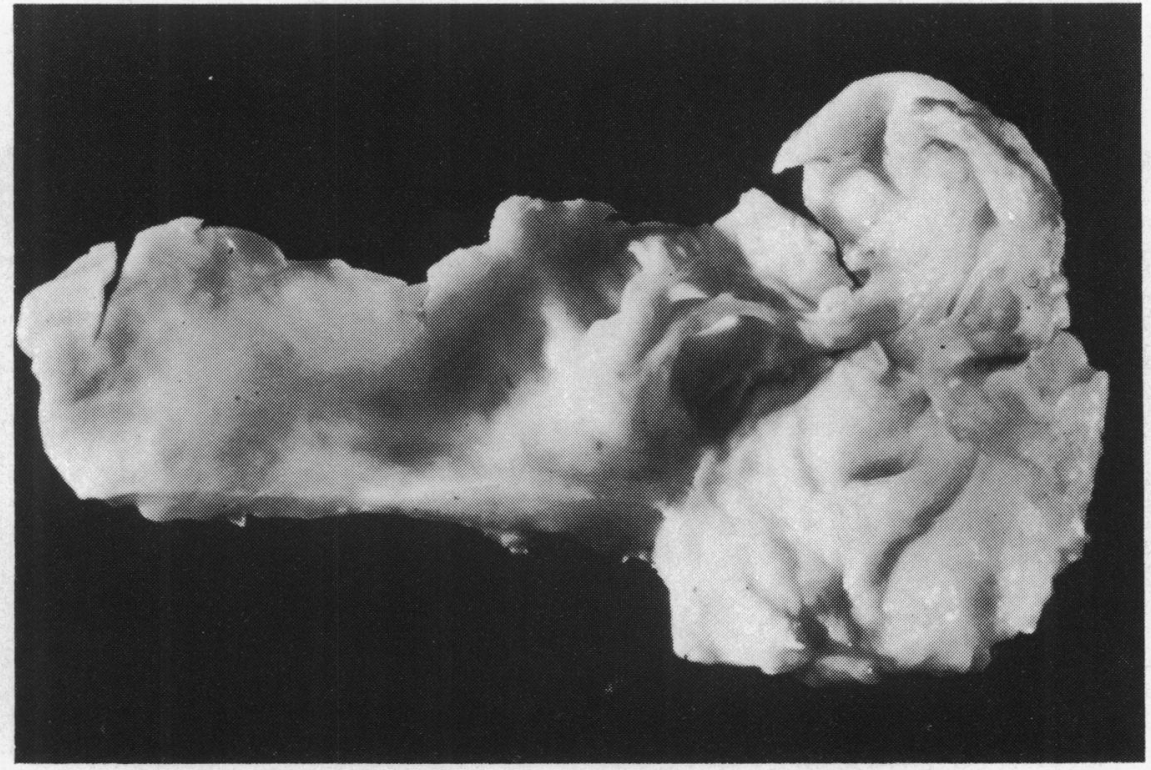

Fig. 3 Resected endomyocardial tissue from the right ventricle of case 1 . 
CASE 2

A previously healthy 24-year-old man presented with a few weeks' history of heart failure, his deteriorating exercise tolerance eventually preventing him from walking short distances on the flat. On examination he looked ill and jaundiced with gross right heart failure. Signs of restrictive cardiomyopathy included a tachycardia at rest of 150 /minute, a raised jugular venous pressure which rose higher on inspiration, and biventricular hypertrophy. There were murmurs of mitral and tricuspid regurgitation and a gallop rhythm. There was an eosinophilia of $5.1 \times 10^{9} / 1$, with mature but vacuolated and degranulated eosinophils in blood films as described in case 1. Despite a wide range of investigations for allergic or parasitic causes, no cause for the eosinophilia was found though the serum IgE was increased to $2840 \mathrm{IU} / \mathrm{ml}$. He was considered to have severe endomyocardial disease with predominant mitral valve involvement caused by the hypereosinophilic syndrome in a quiescent phase.

\section{Preoperative cardiac investigations}

There was slight cardiomegaly and pulmonary oedema in chest radiographs, and electrocardiograms showed sinus rhythm, right axis deviation, and right ventricular hypertrophy. On ambulatory Holter monitoring, frequent multifocal extrasystoles were seen with one episode of supraventricular tachycardia. Cardiac pressure studies are shown in Table 1. A right ventricular angiogram showed an enlarged right ventricle and obliteration of the apex with mild tricuspid regurgitation (Fig. 4). A left ventricular angiogram showed severe mitral regurgitation with a hyperdynamic left ventricle (Fig. 5). The left ventricular cavity was of normal size but the wall and apex had some irregularities. Though he responded initially to treatment with diuretics and warfarin, his exercise tolerance decreased until he was breathless at rest.

\section{Operative findings}

At operation the left ventricle was hypertrophied with a whiter endocardial surface than normal. The mitral valve ring was considerably dilated, with some fusion of the posterior cusps of the mitral valve to the posterior ventricular wall. It was replaced with a 24 mm model 6400 Starr-Edwards prosthesis. Histology showed normal valve cusps, and the attached papillary muscles were mildly hypertrophied with interstitial fibrosis. The left and right atria were dilated and hypertrophied. The right ventricle was also dilated and hypertrophied and had a pale endocardial surface, most obvious at the apex and at the base of the anterior papillary muscle. But as the right-sided lesions were thought to be less haemodynamically significant than those on the left, and as operation would have necessitated sacrifice of the tricuspid valve, endocardial resection and tricuspid valve surgery were not carried out. Two days after operation he developed a severe organic toxic confusional state lasting for three weeks. He was disorientated, with loss of memory, and failed to recognise his relatives. He often sat alone singing to himself. There were no focal cerebral lesions and the cerebrospinal

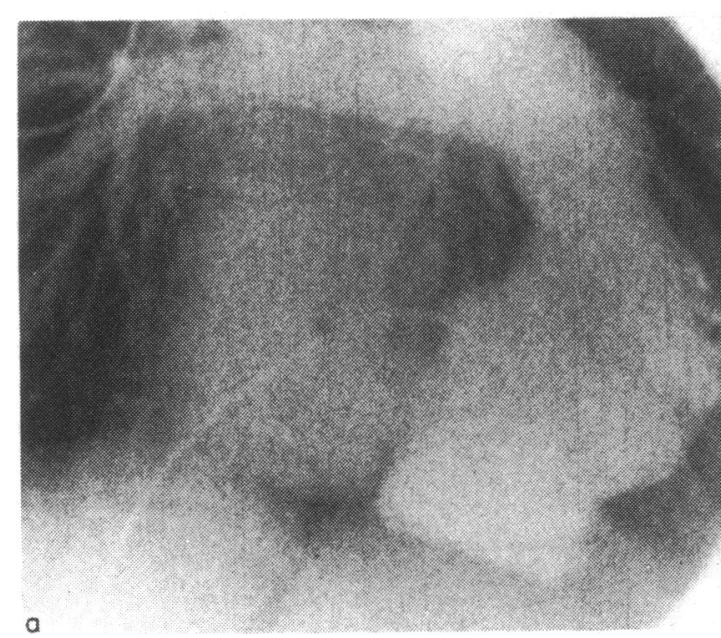

Fig. 4 Right ventricular angiogram, case 2. (a) six months before operation and (b) three months after operation showing no progression of severe endomyocardial fibrosis. Endocardectomy was not performed in this patient. 


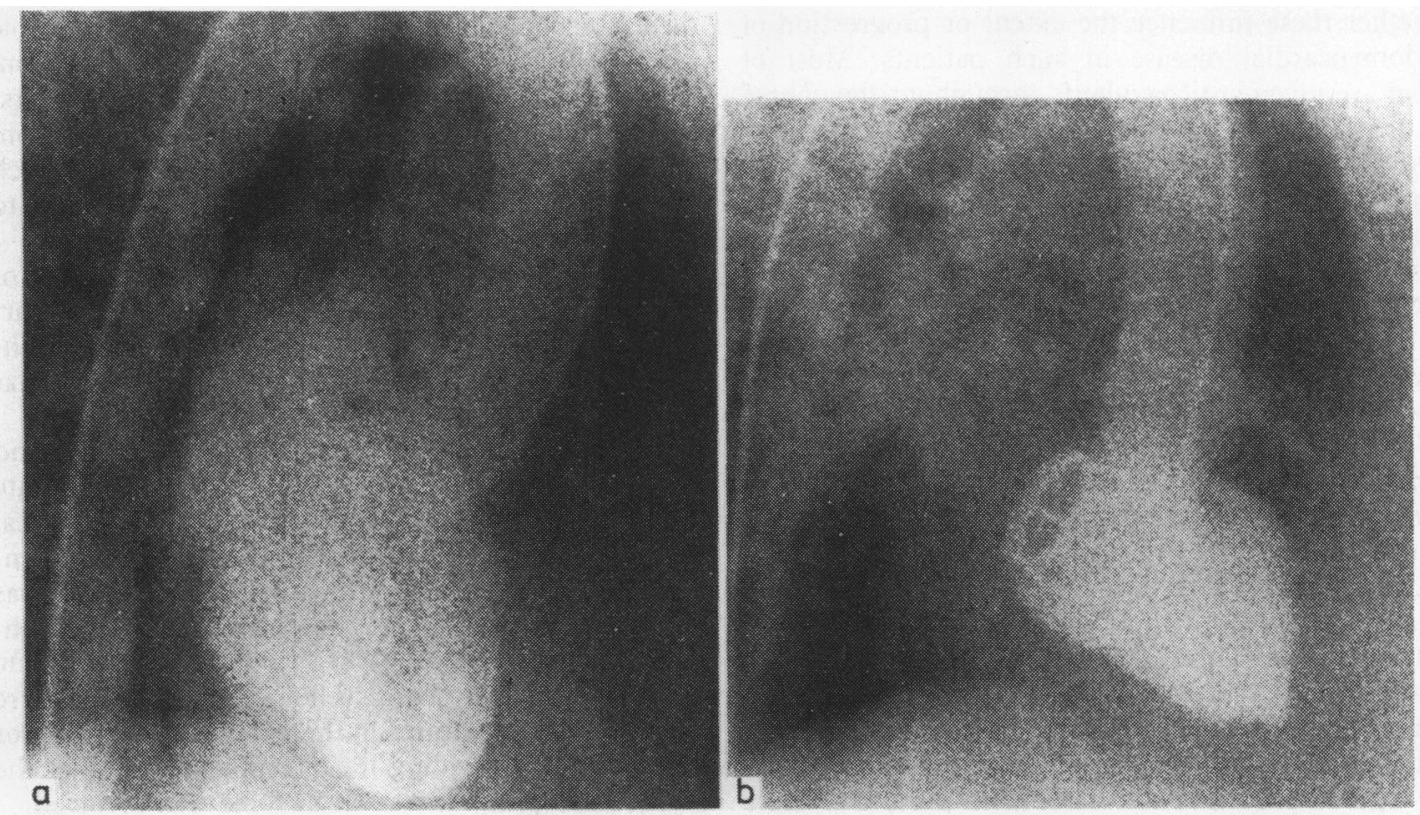

Fig. 5 Left ventricular angiogram, case 2. (a) six months before operation and (b) three months after operation, showing no residual mitral regurgitation after a Starr-Edwards mitral valve replacement. There are slight irregularities of the ventricular wall which have not changed.

fluid protein was $0.65 \mathrm{~g} / \mathrm{l}$. Eosinophils were not present in the cerebrospinal fluid and the eosinophil cationic protein content of the cerebrospinal fluid was not increased.

\section{Postoperative findings}

Three months after the operation he felt well. His mental state was normal and he was now able to manage two flights of stairs without dyspnoea. He no longer required treatment with diuretics. The eosinophilia persisted unchanged. Cardiac catheterisation four months after operation showed no progression of endomyocardial disease (Fig. 4 and 5) and the mitral valve prosthesis was functioning normally (Fig. 5). Nine months after operation he was able to bicycle to work without becoming breathless. The only abnormal physical sign was a raised jugular venous pressure of $6 \mathrm{~cm}$. Ambulatory Holter monitoring at this stage showed only a few ventricular extrasystoles and he has remained well 16 months after operation.

\section{Discussion}

These cases confirm that tricuspid and/or mitral valve surgery for endomyocardial disease can be successful even in patients with the hypereosinophilic syndromes, and suggest that ventricular endocardectomy may be safely carried out without risk of thrombi, emboli, or recurrence at the operative sites. The results should encourage the use of cardiac surgery in patients with severe heart failure caused by endomyocardial disease irrespective of whether they have hypereosinophilia.

Preoperative cardiac assessment was done to determine the relative importance of restriction of filling of each ventricle by endomyocardial fibrosis, obliteration with clot and/or fibrous tissue, and involvement of the mitral or tricuspid valves as in other patients with endomyocardial disease without eosinophilia in the past. The possibility was considered that the heart failure might be responsive to steroids, which have improved cardiac function in a small number of patients with hypereosinophilia and acute myocarditis. ${ }^{12}$ In both patients, however, there were clear structural reasons why surgery should be carried out and the lesions were seen clearly at operation: obliteration of the right ventricle in case 1 and severe mitral regurgitation in case 2 . In the latter, operation had to be carried out urgently because of the presentation of severe heart failure; in the former, two courses of treatment with steroids had been given during the preceding four years. The effects of steroids and cytotoxic drugs on relapses in patients with hypereosinophilic syndromes have been reviewed by Parrillo et al. ${ }^{10}$ It is not known, however, 
whether these influence the extent or progression of endomyocardial disease in such patients. Most of them are given anticoagulants throughout the course of their illness, as emboli and thrombotic complications are common. ${ }^{13}$ In patients who present with hypereosinophilic syndromes without cardiac involvement monitoring of the number of degranulated blood eosinophils has proved to be a useful method of predicting the onset of cardiac complications. ${ }^{13}$

The types of operation which have been carried out previously in 26 patients with endomyocardial disease, with and without an eosinophilia, are shown in Table 2. Four of them had hypereosinophilia at the time of operation and one developed this postoperatively. All 22 patients who did not have eosinophilia at the time of operation had a resection of endocardial tissues. Follow-up studies have shown no local recurrence but the long-term outlook for these patients is still not known. The types of valve replacements which have been used include xenografts, and Starr-Edwards, Beall, Björk-Shiley, and Lillehei Kaster prostheses. There do not appear to be any special problems associated with the use of these valves though two patients have had thrombotic complications. One died after thrombosis of her Björk-Shiley mitral prosthesis 14 months postoperatively, ${ }^{14}$ and the other died 17 months after operation as a result of a recurrence of endomyocardial fibrosis which was associated with a massive eosinophilia. ${ }^{15}$ Dubost, reporting on 12 patients, described one who died 20 days after operation as a result of intractable renal failure and one who died at 20 months from paroxysmal atrioventricular dissociation. His first patient, operated on in 1971, died in 1978 from cirrhosis. His other patients, however, are much improved, the majority of them being able to return to normal work. ${ }^{2}$

There have been few postoperative complications of surgery in patients with endomyocardial disease apart from reports that endocardectomy of the right ventricle may produce complete atrioventricular block requiring pacing. ${ }^{116}$

Both of our patients had hypereosinophilia and developed a severe organic toxic confusional state soon after operation. Despite extensive neurological investigation, including lumbar puncture, brain scan, and computerised axial tomography, no cause was found. The confusion, however, resolved spontaneously within five weeks of operation, leaving no residual neurological or psychological deficit. As there were no special features in the operative procedure or the events surrounding it, it seems possible that the hypereosinophilia itself was in some way involved.

The morphological recognition of eosinophilic endomyocardial disease is well established ${ }^{45}$ and the zonal layering of the thick endocardium is highly characteristic. The striking feature is the extensive thickening of the endocardium which in the normal right ventricle does not exceed $10 \mu \mathrm{m}$. In case 1 it measured as much as $6 \mathrm{~mm}$ in thickness. The disease

Table 2 Reports of patients with endomyocardial disease treated surgically

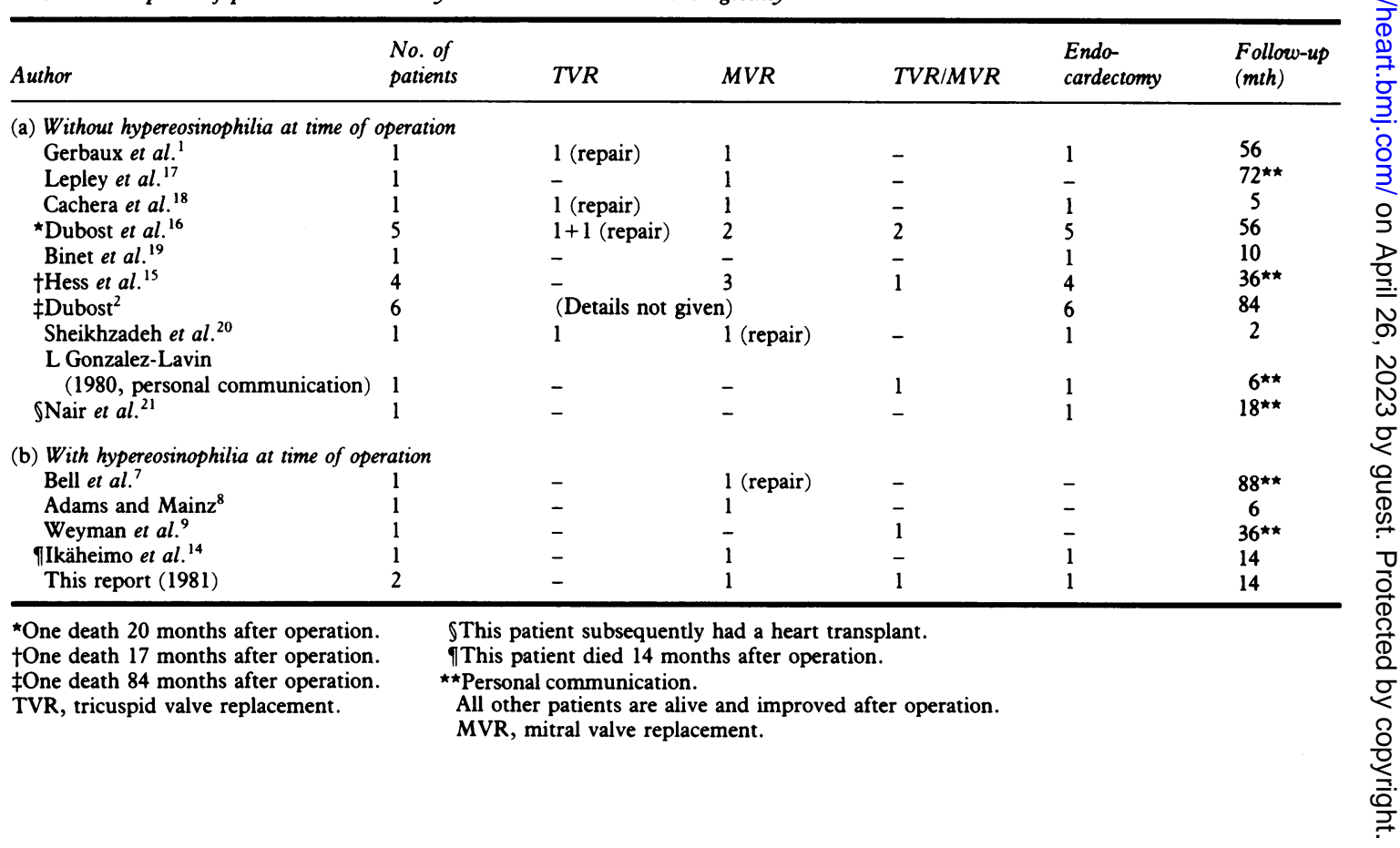


can involve the right or left ventricle separately but biventricular involvement is the form most commonly encountered. ${ }^{5}$

The diagnosis of endomyocardial disease is being made increasingly frequently during life. Because surgical treatment may benefit many of these patients, full cardiological assessment is required. In patients with severe heart failure resulting from valve lesions, simple correction of these can be of great value, as patients with restrictive cardiomyopathy are obviously unable to tolerate even mild valvular regurgitation. The removal of fibrous tissue from affected ventricles should also benefit patients who have obvious restrictive and/or obliterative lesions. These procedures should be considered for all patients with advanced endomyocardial disease, including those with hypereosinophilia. Surgery appears to be a significant step forward in the management of these patients.

We should like to thank C Y C Chew et al. and the British Heart fournal for allowing us to reproduce Fig. 1a and $\mathrm{c}$ and 2a, and Dr J Lister, Windsor Hospital, for referring case 1. The financial support of the British Heart Foundation is gratefully acknowledged.

The study forms part of the Multicentre Research Project on Endomyocardial Diseases of the Scientific Council on Cardiomyopathies of the International Society and Federation of Cardiology.

\section{References}

1 Gerbaux A, Dubost C, Maurice P, et al. Endomyocardite fibreuse observée au cours de la filariose. Ann Med Interne (Paris) 1973; 124: 471-82.

2 Dubost C. Surgery for constrictive fibrous endocarditis. Compr Ther 1979; 7: 28-32.

3 Lancet. Surgery for endocardial fibrosis (Editorial). Lancet 1976; ii; 297-8.

4 Brockington IF, Olsen EGJ. Löffler's endocarditis and Davies' endocardial fibrosis. Am Heart $\mathcal{f}$ 1973; 85: 308-22.

5 Olsen EGJ, Spry CJF. The pathogenesis of Löffler's endomyocardial disease, and its relationship to endomyocardial fibrosis. In: Yu PN, Goodwin JF, eds. Progress in cardiology. Philadelphia: Lea \& Febiger, 1979: 281-303.

6 World Health Organisation Report of the WHO/ISFC task force on the definition and classification of cardiomyopathies. Br Heart F 1980; 44: 672-3.
7 Bell JA, Jenkins BS, Webb-Peploe MM. Clinical, haemodynamic and angiographic findings in Löffler's eosinophilic endocarditis. Br Heart 7 1976; 38: 541-8.

8 Adams HW, Mainz DL. Eosinophilic ascites: a case report and review of the literature. Am $\mathcal{F}$ Dig Dis 1977; 22: 40-2.

9 Weyman AE, Rankin R, King H. Löffler's endocarditis presenting as mitral and tricuspid stenosis. Am $\mathcal{F}$ Cardiol 1977; 40: 438-44.

10 Parrillo JE, Borer JS, Henry WL, Wolff SM, Fauci AS. The cardiovascular manifestations of the hypereosinophilic syndrome. Am F Med 1979; 67: 572-82.

11 Chew CYC, Ziady GM, Raphael MJ, Nellen M, Oakley CM. Primary restrictive cardiomyopathy. Non-tropical endocardial fibrosis and hypereosinophilic heart disease. Br Heart f 1977; 39: 399-413.

12 Davies J, Spry CJF, Olsen EGJ, Du Perez G, Oakley CM, Goodwin JF. Cardiovascular features of eleven patients with eosinophilic endomyocardial disease. 1981. Submitted for publication.

13 Spry CJF, Davies J, Tai P-C, Olsen EGJ, Oakley CM, Goodwin JF. Clinical features of fifteen patients with the hypereosinophilic syndrome. 1981. Submitted for publication.

14 Ikäheimo MJ, Kärkölä PJ, Takkunen JT. Surgical treatment of Löffler's eosinophilic endocarditis. Br Heart f 1981; 45: 729-32.

15 Hess OM, Turina M, Senning A, Goebel NH, Scholer Y, Krayenbuehl, HP. Pre- and postoperative findings in patients with endomyocardial fibrosis. Br Heart $\mathcal{F}$ 1978; 40: 406-15.

16 Dubost C, Maurice P, Gerbaux A, et al. The surgical treatment of constrictive fibrous endocarditis. Ann Surg 1976; 184: 303-7.

17 Lepley D, Jr, Aris A, Korns ME, Walker JA, D'Cunha RM. Endomyocardial fibrosis: a surgical approach. Ann Thorac Surg 1974; 18: 626-33.

18 Cachera JP, Poulain H, Menasche Ph. Endocardie fibreuse d'origine filarienne. Trop Cardiol 1976; 2: (6), 79-89.

19 Binet JP, Pernod J, Kermarec J, et al. Endocardite constrictive fibroblastique. A propos d'une forme localisée au ventricule gauche. Arch Mal Coeur 1977; 70: 163-8.

20 Sheikhzadeh AH, Tarbiat S, Nazarian I, Aryanpur I, Senning $\AA$. Constrictive endocarditis. Report of a case with successful surgery. Br Heart $\mathcal{F}$ 1979; 42: 224-8.

21 Nair U, Evans T, Oakley D. Surgical treatment of endomyocardial fibrosis with preservation of mitral valve. Br Heart $\mathcal{F}$ 1980; 43: 357-9.

Requests for reprints to Dr Christopher Spry, Department of Immunology, Royal Postgraduate Medical School, 150 Ducane Road, London W12 0HS. 